\title{
GÊNERO E TRAUMA
}

\section{Gláucio Ary Dillon Soares* \\ Dayse Miranda**}

Resumo: As conseqüências sociais e psicológicas da violência urbana sobre os parentes e amigos de pessoas vitimadas por mortes violentas (homicídio, suicídio ou acidentes) são analisadas à luz das diferenças de gênero. A literatura especializada nesta área propõe que mulheres e homens vivenciam experiências traumáticas de forma peculiar. Porém, os traumas típicos são diferentes em cada gênero, deixando em aberto a questão sobre quanto das diferenças entre as respostas se devem a gênero e quanto se devem ao tipo de trauma. Testamos a hipótese de que as mulheres são mais suscetíveis à desordem de estresse pós-trauma (DEPT) numa situação traumática comum, usando dados qualitativos e quantitativos. Comparamos os sintomas do trauma e as percepções sobre o significado da perda de seus entes queridos. A amostra, de 425 mulheres (62\%) e 265 homens (38\%), foi retirada de uma lista de parentes de pessoas que sofreram morte violenta na cidade do Rio de Janeiro. Incluímos trinta relatos de parentes e amigos próximos das vítimas diretas. Os resultados revelaram que $54 \%$ das mulheres e $41 \%$ dos homens tiveram o cotidiano alterado depois da morte de um parente/amigo. Há diferenças estatisticamente significativas nos problemas de saúde e na diversão. Essa área foi a mais afetada, atingindo metade dos entrevistados. Uma variável intimamente correlacionada com os sintomas da DEPT é o contato com o corpo: controlando a extensão do contato (fez o reconhecimento do corpo; viu, mas não reconheceu

Ph.D. em Sociologia, Washington University, St. Louis; pesquisador Datacrime e Iuperj. E-mail: soares_7@terra.com.br.

** Socióloga, mestre em sociologia pelo Iuperj, doutoranda do departamento de Ciência Política da USP e pesquisadora da Cepia (Cidadania, Estudos, Pesquisa, Informação e Ação) nas áreas de gênero e violência. E-mail: dayse@cepia.org.br ou daysemira@yahoo.com.br.

Os autores agradecem as contribuições e sugestões de Doriam Borges, Joana Nunes e Sabrina Lima, as quais foram fundamentais para a execução da pesquisa As vítimas ocultas da violência no município do Rio de Janeiro, realizada no Centro de Estudos e Segurança e Cidadania (CESeC) e financiada parcialmente pela Faperj, cujos dados são apresentados neste artigo.

Artigo recebido em 29 nov. 2004; aprovado em 13 jan. 2005. 
e nem viu nem reconheceu). Em cada uma dessas categorias, as mulheres foram mais afetadas do que os homens. $\mathrm{O}$ artigo conclui que as mulheres sentem mais as perdas do que os homens, mas que parte das diferenças não são internas aos gêneros, mas externas a eles, dependendo das interações e dos contatos pessoais.

Palavras-chave: violência urbana, vítima oculta, estresse pós-trauma, DEPT, gênero.

Estudos recentes na área de Psiquiatria e de Psicologia social revelaram que experiências traumáticas são vivenciadas distintamente por homens e mulheres. De acordo com Breslau, Davis, Andreski \& Peterson (1991), Breslau, Davis, Andreski, Peterson \& Schultz (1997), Breslau, Kessler, Schultz, Davis \& Andreski (1998), Stein, Walker, Hazen \& Forde (1997), as mulheres são mais suscetíveis a desenvolver a Desordem de Estresse Pós-Trauma (DEPT ou PTSD, em inglês), dependendo da categoria de trauma. Como fatores culturais interferem nas diferenças entre gêneros, não é possível extrapolar para o Brasil os resultados de pesquisas realizados em culturas com importantes diferenças em relação à brasileira. Para tal, precisamos investigar como as categorias trauma e gênero estão relacionadas no Brasil.

Muitos modelos analíticos sobre a suscetibilidade feminina à Desordem de Estresse Pós-Trauma (DEPT) fundamentam-se teoricamente na Psicologia e, sobretudo, na Psiquiatria. Stein, por exemplo, argumenta que a diferença na DEPT deve-se à freqüencia diferencial e aos tipos diferentes de trauma vivenciados por homens e mulheres. Seriam traumas relativamente diferentes dos sofridos pelos homens, que ocorrem com frequiência diferentes. Contudo, esta hipótese não esclarece o porquê das mulheres serem mais suscetíveis à DEPT do que os homens, numa situação traumática semelhante. Por outro lado, Cortina \& Pimlott-Kubiak (2003) refutam esta tese da suscetibilidade feminina à DEPT, a partir de um estudo sobre as reações psicopatológicas de homens e mulheres em situações de violência (abuso sexual e emocional e agressão física). Os autores não encontraram nenhum efeito interativo significativo entre gênero e agressões interpessoais. 
Kathleen Brady (2004) acredita que as diferenças de gênero têm duas dimensões distintas: social e biogenética. A primeira, segundo a autora, consiste nos fatores socioculturais que diferenciam os papéis dos homens e das mulheres na estrutura social; a segunda refere-se ao efeito dos respectivos sistemas biológicos sobre a DEPT e viceversa. Seus argumentos sublinham as diferenças entre as reações emocionais de homens e mulheres frente a incidentes traumáticos. As mulheres desenvolveriam sintomas emocionais que levariam a um diagnóstico de depressão e ansiedade, ao passo que os homens reagiriam a uma experiência traumática com expressões e atitudes de irritabilidade e impulsividade, e recorreriam com maior freqüência a substâncias tóxicas. Ou seja: estímulos semelhantes, reações diferentes.

Outros fatores se associam às conseqüências diretas de uma agressão física, ou aos impactos provocados por testemunhar um episódio traumático, como presenciar alguém ser ferido ou morto (Blanchard, Hickling, Mitnick, Taylor, Loos \& Bukley, 1995; Shalev, Peri, Canetti \& Schreiber, 1996). Há pesquisadores que discutem as diferenças de gênero a partir das reações e percepções cognitivas dos indivíduos sobre o incidente traumático. De acordo com o modelo cognitivo da DEPT, fatores de ordem emotiva e representações individuais ajudam a explicar as diferenças de gênero. Esta linha interpretativa, associada com o nome de Edna Foa, afirma que a maneira pela qual as vítimas interpretam simbolicamente o evento traumático está correlacionada com os valores, os pensamentos e as imagens construídas individualmente (Foa \& Kozark, 1986; Foa \& Riggs, 1993; Foa \& Rothbaum, 1998).

Foa \& Tolin (2002) explicam que as diferenças individuais em reagir e sentir as consequiências de um evento traumático estão vinculadas a representações simbólicas, combinadas com as características psicológicas e biogenéticas de cada gênero. Em virtude disso, a DEPT é concebida como um medo patológico. Tratar-se-ia de uma desordem "estressante" correspondente às más associações (desvinculadas do processo "real" do evento traumático) com a estrutura do medo "construído". Nessa perspectiva, seriam as 
associações cognitivas que determinariam a vulnerabilidade de gênero à DEPT.

Outros estudos, também sobre as diferenças de gênero e trauma, enfatizam os fatores neurobiológicos, cognitivos e psicossociais, preferindo as explicações individuais e inter-pessoais. Para esses pesquisadores, em situações traumáticas, as "feridas" são mais comuns entre as mulheres do que entre homens devido à especificidade da "personalidade de cada gênero".

Essas leituras, feitas dentro de culturas distintas, não esclarecem em que medida fatores externos aos gêneros, como os socioculturais e estruturais afetam as diferenças entre eles. Pesquisas realizadas em contextos cada vez mais diferenciados entre si ampliaram a problemática, revelando que algumas associações eram cultura-dependentes.

A pesquisa "Vítimas Ocultas da Violência," desenvolvida na cidade do Rio de Janeiro, também encontrou algumas diferenças de gênero entre os parentes e amigos que perderam pessoas queridas por morte violenta. É nesse sentido que o presente artigo se propõe a demonstrar a relação entre trauma e gênero em situações traumáticas semelhantes. Ou seja, examinamos como os homens e as mulheres entrevistadas, vítimas indiretas por mortes violentas (homicídio, suicídio e acidentes), sofrem e vivenciam a perda de seus entes queridos.

\section{Métodos e dados}

De fevereiro a março do ano de 2003, a equipe de pesquisa "Vítimas Ocultas" realizou 20 entrevistas abertas com familiares e amigos, que tiveram uma pessoa vitimada por morte violenta. ${ }^{1}$ As primeiras entrevistas foram feitas com parentes, amigos ou conhecidos da equipe de pesquisadores tanto no Centro de Estudos de Segurança e Cidadania (CESeC), quanto no domicílio do entrevistado - conforme a escolha deste - sendo gravadas e durando até duas horas. Foi elaborado um roteiro da perguntas, primariamente a partir de uma extensa bibliografia sobre o tema e, secundariamente, buscando 
especificidades da DEPT na cultura brasileira. Privilegiamos novas questões relativas às características socioeconômicas e culturais do entrevistado; ao tipo de morte violenta (homicídio, acidente e suicídio) vivenciada pelo entrevistado; às consequiências da perda do ente na vida do entrevistado; e à re-socialização da vítima secundária. Posteriormente, para ampliar e diversificar a amostra, foi feito um levantamento de sindicatos de profissões cujo exercício implicasse maior risco de vida aos seus associados, como, por exemplo, os sindicatos de taxistas, de motoristas de ônibus, de jornalistas, de seguranças, etc. Além disso, buscamos contatos com associações de proteção à testemunha e de combate à violência. Essas vítimas secundárias contribuíram duplamente para a operacionalização deste trabalho, dando entrevistas e cedendo referências a outras famílias de pessoas também vitimadas por homicídio, suicídio ou acidentes.

A análise e a reflexão sobre essas narrativas e a bibliografia resultaram na identificação de variáveis, algumas novas, na categorização das mesmas e na elaboração do questionário piloto. Dentre as categorias selecionadas destacam-se: datas, sono, religião, lembrança, premonições, flashbacks, medo, relações da família/amigos, polícia, tráfico e droga, e poder público. Embora o número de entrevistas tenha sido modesto, várias categorias se repetiram em quase todos os vinte relatos, o que justificou a sua inclusão no questionário.

A coordenação da pesquisa iniciou, em fevereiro de 2003, negociações junto a várias instituições situadas no Rio de Janeiro, visando obter autorização para acessar os cadastros das vítimas secundárias, solicitando entrevistas que, evidentemente, eram voluntárias, para as quais foi necessária a permissão explícita dos entrevistados. A pesquisa nos arquivos das instituições estendeu-se por aproximadamente três meses. Em abril, foi iniciada a primeira coleta de informações sobre os familiares e/ou amigos de pessoas vitimadas por morte violentas mediante análise dos laudos cadavéricos.

Durante esse período foi elaborada também uma base de dados referente aos anos de 1995, 2000, 2001 e 2002. Construído o 
questionário, foi efetuado um pré-teste, que teve como metas: (a) averiguar se os entrevistados compreendiam bem o vocabulário utilizado, se as variáveis escolhidas e a ordem dos blocos temáticos eram adequadas; (b) verificar se o questionário alcançava níveis mais profundos, através da técnica de probes em perguntas abertas; (c) avaliar a reação dos entrevistados, dado o caráter peculiar da pesquisa; e (d) conhecer as dificuldades referentes ao cadastro de domicílios utilizado pela pesquisa.

O pré-teste foi feito em duas etapas. Na primeira, corrigimos o conteúdo e a forma do questionário, e identificamos vários problemas a enfrentar no trabalho de campo. A segunda foi usada para treinar os entrevistadores. Após o treinamento no escritório, cada entrevistador aplicou dois questionários a vítimas reais. Dessa forma, esses entrevistadores familiarizaram-se com o questionário, com as dificuldades referentes aos endereços, ${ }^{2}$ com o tema da pesquisa e, principalmente, com as dificuldades da entrevista com essa população.

Para a amostra foram selecionados 1.128 domicílios de um cadastro criado a partir de uma lista de parentes de pessoas que sofreram morte violenta na cidade do Rio de Janeiro. Desse total, cerca de 90 endereços tinham mais de uma casa e 192 possuíam endereços errados. Em 12,4\% dos domicílios visitados, as entrevistas foram recusadas. Para um total de 519 domicílios (46,0\%), foi possível realizar a pesquisa. Nesses domicílios, foram aplicados 856 questionários. Desse total, 19,4\% dos entrevistados não eram vítimas secundárias, enquanto que 80,6\%, isto é, 690 pessoas possuíam familiares ou amigos mortos de forma violenta (434 domicílios).

As escalas de DEPT usadas fora do País são, em sua maioria, extensas, sendo aplicadas em situações clínicas, juntamente com entrevistas clínicas. Há escalas menores. Como trabalhamos no nível de sintomas por acreditar que um diagnóstico correto requer entrevista e exame clínico, incluímos vários itens dessas escalas que se referiam a cortes diferentes de intensidade (desde alguns sintomas que muitos apresentavam até outros que poucos apresentavam) e elaboramos novos itens para incluir aspectos que surgiram nas entrevistas 
qualitativas. Assim, esta pesquisa não pretendeu, nem pode, diagnosticar ninguém com ou sem DEPT; analisamos apenas sintomas. Incluímos também dados relacionados aos perfis emocional, afetivo e socioeconômico dos entrevistados.

Esses parâmetros reforçaram a hipótese de que fatores estruturais e contextuais, combinados com aspectos psicológicos e emocionais, se correlacionam com a forma pela qual as vítimas reagem e convivem após a perda de um parente/amigo por morte violenta.

A pesquisa não avançou no sentido de esclarecer a capacidade explicativa de fatores contextuais, como capital social, renda, escolaridade, status ocupacional e bairro sobre as diferenças entre os gêneros em desenvolver a DEPT. Contudo, no plano empírico, as especificidades de gênero foram entendidas a partir de dados macroestruturais e de informações concernentes aos sintomas da DEPT. No nível teórico, os resultados foram interpretados à luz de argumentos psicossociais e culturalistas.

\section{Análises}

Grande parte da população entrevistada reside nas áreas de alto risco de violência, em precárias condições infra-estruturais. É predominantemente negra (58\% das mulheres e $54 \%$ dos homens), possui nível escolaridade baixo (51\% das mulheres e $48 \%$ dos homens) e declara fazer parte do grupo de faixas de renda de 1 a 2 salários mínimos (25\% das mulheres e $48 \%$ dos homens).

Para entender a relação entre trauma e gênero, recorremos a perguntas relativas às mudanças no dia-a-dia das vítimas secundárias após a morte de um ente querido, às reações e aos sintomas (flashbacks, reações físicas, emocionais e os efeitos das lembranças da morte, tais como:

- Depois da morte do(a) mudou alguma coisa no seu dia-a-dia? 
- Em geral, o(a) $\operatorname{Sr}(a)$ costuma se lembrar da morte do(a) ?

- Essas lembranças motivam o(a) $\operatorname{Sr}(a)$ a ter reações físicas como: problemas para respirar (falta de ar), coração batendo rápido, suor, fraqueza nas pernas ("perna mole") ou diarréia?

- Estas lembranças motivam o(a) $\operatorname{Sr}($ a) a ter reações emocionais como: tristeza, chorar, depressão ou distração?

- Cenas relacionadas a essa morte aparecem na sua cabeça de repente?

Quando perguntamos aos entrevistados se tiveram o cotidiano alterado depois da morte de um parente/amigo, 54\% das mulheres e $41 \%$ dos homens responderam que sim. Esses resultados podem ser observados no Gráfico 1.

\section{Gráfico 1 - Entrevistados que tiveram seu dia-a-dia alterado} após a morte de parente/amigo, segundo gênero

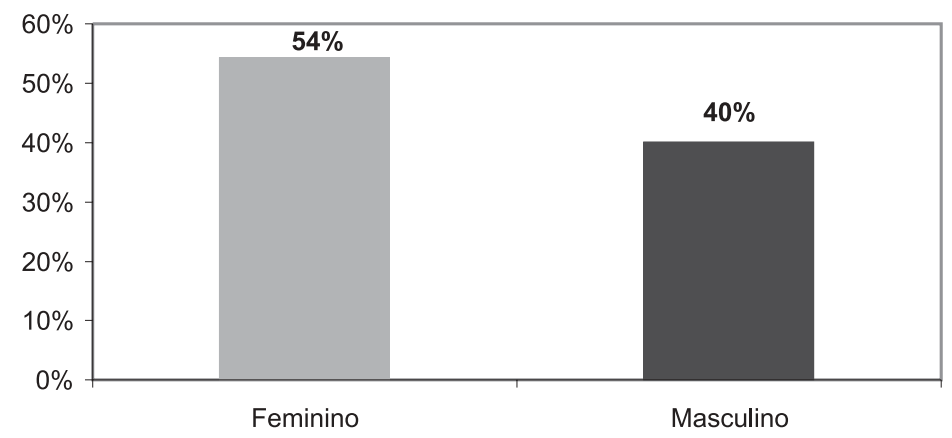

Percentualmente, as feridas marcadas por experiências traumáticas são mais comuns entre as mulheres do que entre os homens, embora ambos os gêneros sejam afetados. A diferença, de quatorze pontos percentuais, é estatisticamente significativa, embora modesta. ${ }^{3}$

Ask Elklit (2002), da Universidade de Aarhus, na Dinamarca, estudou uma amostra representativa dos alunos da oitava série, média 
de 14 anos e meio de idade. Oitenta e sete porcento das meninas e $78 \%$ dos meninos tinham tido pelo menos um evento traumático na vida, sendo que os mais comuns eram a morte de um familiar, ameaças de violência, tentativas de suicídio, doenças graves, acidentes, estupro e abuso infantil. Alguns desses eventos negativos estavam associados com o gênero (estupro mais freqüente entre meninas), a educação dos pais e não viver com o pai e a mãe. A prevalência da DEPT em qualquer momento da vida foi $9 \%$, e outros $14 \%$ apresentavam níveis subclínicos da desordem. Esta amostra, na Dinamarca, com jovens adolescentes, também evidencia que, uma vez expostas a acontecimentos traumáticos, as mulheres apresentam o dobro da prevalência da DEPT.

Nossa pesquisa revela que houve mudanças no dia-a-dia dos entrevistados no que diz respeito ao trabalho, à relação com familiares e amigos, à diversão e aos estudos, mas a mais freqüente foi a cessação da diversão (Gráfico 2).

\section{Gráfico 2 - Mudanças no cotidiano após a morte de parente/amigo, segundo gênero}

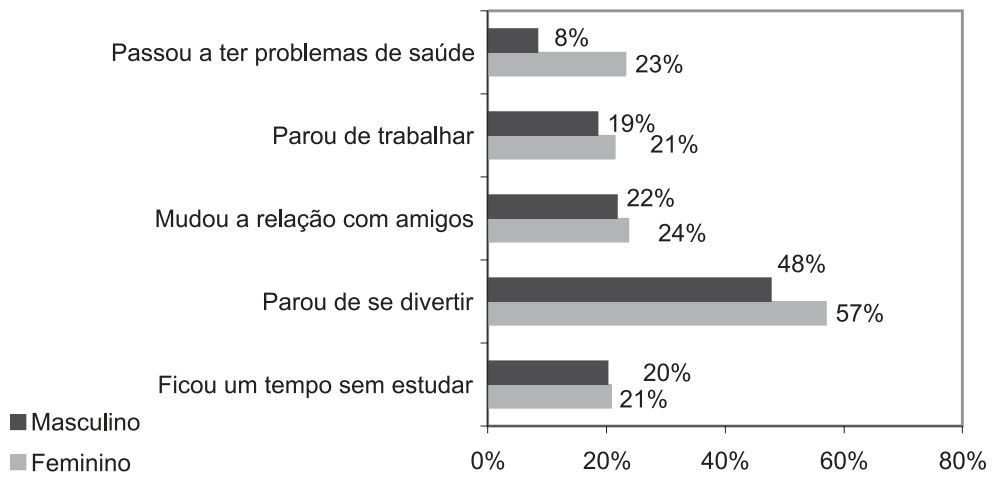

Há diferenças entre os gêneros nos problemas de saúde, no trabalhar e na perda do interesse de se divertir e em outras atividades, mas nem todas são significativas. Nos problemas de saúde a diferença é significativa no nível de $0,000 .{ }^{4} \mathrm{~A}$ outra atividade que exibe diferença 
entre os gêneros, estatisticamente significativa, refere-se à diversão. Essa área foi a mais afetada, em ambos os gêneros, atingindo, aproximadamente, metade dos entrevistados.

A leitura das transcrições das entrevistas perde informações. Todos os analistas da base quantitativa realizaram entrevistas qualitativas, chegando à conclusão esperada que uma grande contribuição das entrevistas, particularmente das qualitativas, deriva de que, muitas vezes, os respondentes expressam essas alterações com entonações, gestos e reações emocionais - às vezes melhor do que verbalmente. Esse "quadro comportamental" encontra expressão apenas parcial na fala. Essa constatação confirma o que pesquisadores experimentados sabem: alguns entrevistados não expressam verbalmente com facilidade o efeito do trauma em suas vidas. Em alguns deles só foi possível detectar a emotividade na observação do seu comportamento. Evidentemente, outros exibiram comportamentos e relatos "frios" e "distantes" ao longo da entrevista.

Pesquisas desenvolvidas na Califórnia (USA) confirmam que o estresse pós-trauma (DEPT) e os problemas de saúde das vítimas estão relacionados, especialmente entre as mulheres. De acordo com Susan Frayne, a desordem de estresse pós-trauma e as doenças físicas estão correlacionadas com mulheres com e sem diagnóstico de depressão. A pesquisa evidencia que pacientes com sintomas da DEPT apresentam problemas de saúde como doenças físicas, dores e baixa energia. As mudanças na vida cotidiana também são visíveis.

Os relatos selecionados mostram mudanças na estrutura familiar, nos hábitos e práticas do dia-a-dia, como mudar de residência; deixar de se divertir, e deterioro da saúde da vítima secundária. Quando pedimos a uma das entrevistadas que falasse um pouco das mudanças depois da morte do seu irmão, ela respondeu:

A minha família continua morando lá em cima, mas eu me mudei definitivamente para aqui pra baixo. $\mathrm{O}$ foco da violência era em todo lado, entendeu? Apesar de eu ter muita preocupação com a minha família, eu tinha mais comigo. Eu tinha muitos amigos que eram polícias, entendeu? Eu tinha medo. Eu tinha psicose dos bandidos descobrirem. "Será que eles vão descobri que eu falo com eles?" Eu 
ficava com psicose na cabeça deles só olharem para mim, eles iriam descobri, entendeu? Então, eu rompi definitivamente com o pessoal lá de cima. Eu não subia na casa dos meus pais, eu só ficava em casa. Não andava mais de Kombi, eu só andava a pé. (Neta de uma vítima de homicídio)

O desabafo dessa moça mostra que a morte de um parente próximo afeta a forma de uma pessoa se relacionar com os seus pares, e também muda o seu comportamento quotidiano, por exemplo, o de "evitar lugares". Esse sintoma foi denominado pela literatura internacional de avoidance behavior. Fizemos a mesma pergunta a uma jovem que perdeu o avô por homicídio.

Olha, pelo que a gente conversa a morte do meu vô desestruturou a família [...] Era ele que resolvia os conflitos, todinhos. (Neta de uma vítima de homicídio)

O que é marcante? Ah, sei lá, assim, minha vida mudou totalmente; eu tinha marido que eu ia todo final de semana sair, que eu saia durante a semana, que brincava com meu filho, e a pessoa que me amava (choro).

Sei lá, tudo; foi tudo. (Mãe de uma vítima de homicídio).

A desintegração familiar é perceptível em vários relatos. Em alguns casos, a morte provocou o rompimento dos laços afetivos na família; em outros, o agravamento da saúde. Um homem atribui os seus problemas de saúde à perda de seu filho vitimado também por homicídio. Quando perguntamos a um pai vitimado pela perda de um filho por homicídio sobre a sua saúde depois deste incidente, ele respondeu:

Eu tenho pressão alta. Eu sou hipertenso.

O sr. sabe o motivo dessa doença?

O motivo eu nem sei, mas atacou mais depois da morte do meu filho. Eu já tinha, mas depois da morte do meu filho atacou mais. (Pai de uma vítima de homicídio)

Quando analisamos as diferenças entre homens e mulheres que tiveram contato ou reconheceram o cadáver, nosso poder de explicação se amplia. 


\section{Gráfico 3 - Alteração no cotidiano das mulheres entrevistadas, segundo ter reconhecido ou visto o corpo}

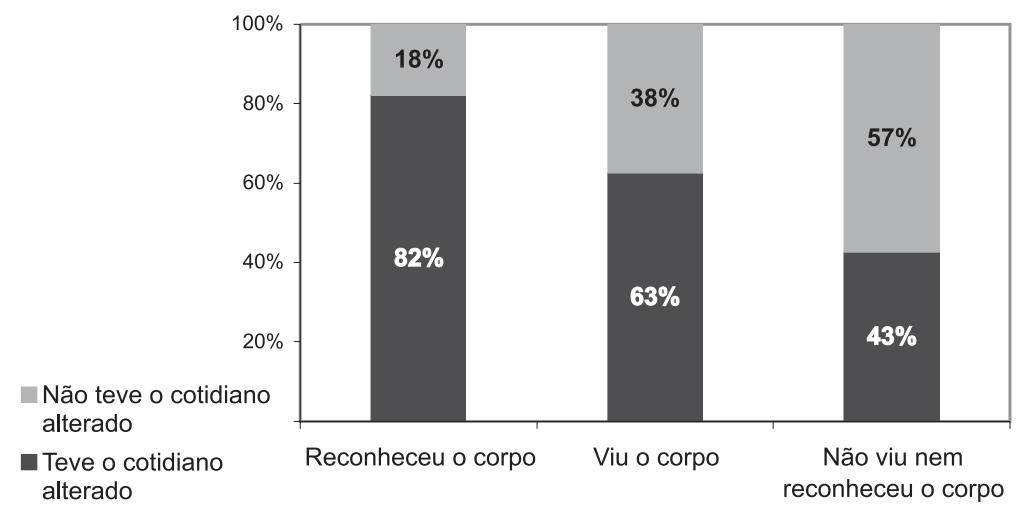

Oitenta e dois porcento das mulheres que reconheceram o cadáver declararam ter tido o cotidiano alterado; entre as que tiveram contato com o corpo, mas não o reconheceram, a percentagem é $63 \%$. Do outro lado, $43 \%$ das mulheres que não viram e nem reconheceram o corpo responderam ter tido o seu cotidiano alterado. Neste grupo, a maioria não teve o quotidiano alterado. Esses resultados sublinham o efeito de "ter contato com o cadáver", particularmente de identificá-lo, sobre a percepção e sensação do trauma desenvolvido pelas vítimas. Essa diferença também é estatisticamente significativa. ${ }^{5}$ A fala abaixo retrata o impacto do contato com o corpo sobre as emoções e sensações das mulheres:

O que me marcou demais é a imagem do rosto dele morto, de olho aberto. Quando eu penso nele vem aquela imagem. E ficou [...] Então ficou aquela imagem da silhueta dele e dessa imagem dele caído no chão. Essas são as imagens mais fortes que eu tenho na minha cabeça. (Tia de uma vítima de homicídio).

Encontramos efeitos semelhantes sobre os homens. No entanto, não há diferenças significativas entre os que reconheceram o cadáver e os que somente viram. Cinqüenta porcento dos respondentes que tiveram contato ou que reconheceram o corpo declararam ter tido o cotidiano alterado. Quando comparamos homens e mulheres que tiveram contato com o corpo, verificamos que as respostas femininas (de ambos os grupos) são mais intensas do que as dos homens. 


\section{Gráfico 4 - Alteração no cotidiano dos homens entrevistados, segundo ter reconhecido ou visto o corpo}

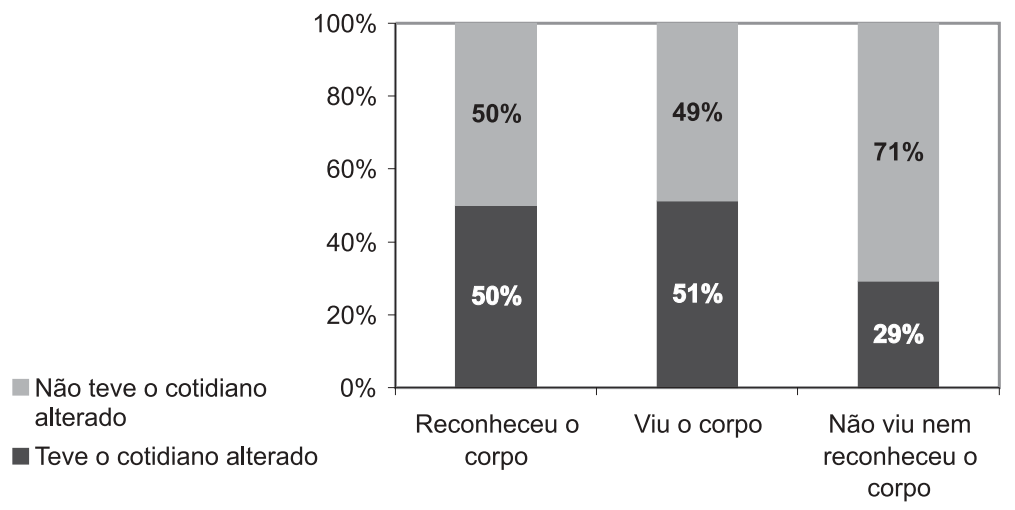

A diferença percentual é visível entre homens e mulheres que não viram e não reconheceram o corpo: $71 \%$ dos homens responderam que o cotidiano permaneceu inalterado, em contraste com apenas $57 \%$ das mulheres. É uma diferença de 14 pontos percentuais, que é estatisticamente significativa. ${ }^{6} \mathrm{O}$ contato com $o$ cadáver tem peso sobre as reações emocionais das vítimas, particularmente as femininas.

As entrevistas qualitativas esclarecem o efeito da experiência "ter contato com o cadáver" nas vítimas secundárias. Nas palavras de um pai sensibilizado por ter perdido o seu filho num acidente de automóvel:

O sr. foi fazer o reconhecimento do corpo?

É,fui.

Foi bem tratado lá?

É, normal.

O sr. lembra desse dia exatamente?

Lembro. Eu tenho isso na memória.

Tem alguma imagem que tenha ficado na sua memória?

Foi ... gravei, eu gravei a imagem de reconhecer o corpo, porque ele 
estava num aspecto todo ruim. Ele estava com a mão toda dura. Foi horrível para mim. (Pai de uma vítima de acidente)

Então, o sr. foi lá e viu o corpo lá?

E vi o corpo do meu pai. Quando eu cheguei lá, esse primo da minha esposa não sabia que era ... por enquanto eu não sabia que era esse primo que tinha envolvido nesse caso, estava botando vela no corpo! Vela! Velando. "Eu falei: Ué, o que que houve?" "Pô, deram um tiro no seu pai". "Deram um tiro no meu pai?" Eu fiquei totalmente desesperado. Aí, vai pra aqui, eu ainda cheguei apertar assim procurando a bala, que local da bala, aonde é que foi. Eu não estou vendo, nem sinal de sangue, entendeu? Então, apertando ele chegou a responder. Ele olhou pra mim. E eu apertei e pensei assim "Meu Deus do céu, o que é que está havendo?" Aí, eu fiquei tão desesperado que eu não sabia o que fazer. A única que coisa que eu fui procurar, que eu vi, foi queimado. (Filho de uma vítima de homicídio)

Esses trechos evidenciam o efeito do contato com o cadáver sobre a vida cotidiana. É possível admitir certa endogeneidade nessa equação, particularmente se hipotetizarmos que as pessoas designadas para reconhecer o corpo talvez sejam mais próximas socialmente ao morto. Não obstante, também é possível argumentar que as pessoas mais suscetíveis são mais "protegidas" neste ritual. ${ }^{7}$ Nossos dados mostram que a percentagem de filhos e filhas $(4,6 \%)$ e avôs e avós $(0,3 \%)$ que fizeram essa ingrata tarefa é reduzida.

Existem diferenças de gênero no sentir a perda de entes queridos. Essa constatação pode ser visualizada no gráfico do leque de sensibilidade que apresenta as médias do número de itens que evocam lembranças, de quantas coisas diferentes estimulam essas lembranças. Chamamos ao conjunto desses itens de leque de sensibilidade. Construímos três leques cujas escalas são decrescentes. O maior é composto por todos os 11 itens sobre os que fizemos perguntas. O leque 1 é composto por 10 itens (lugares, pessoas, objetos, notícias, horários, luzes, datas, cheiros, vozes ou sons, situações parecidas com o acontecido). Por último, o leque 2 é constituído por 9 itens (lugares, pessoas, objetos, notícias, horários, luzes, datas, cheiros, vozes ou sons). O leque 2 retira o viés implícito no item "situações parecidas com o acontecido". 


\section{Gráfico 5 - Níveis médios de sensibilidade segundo gênero}

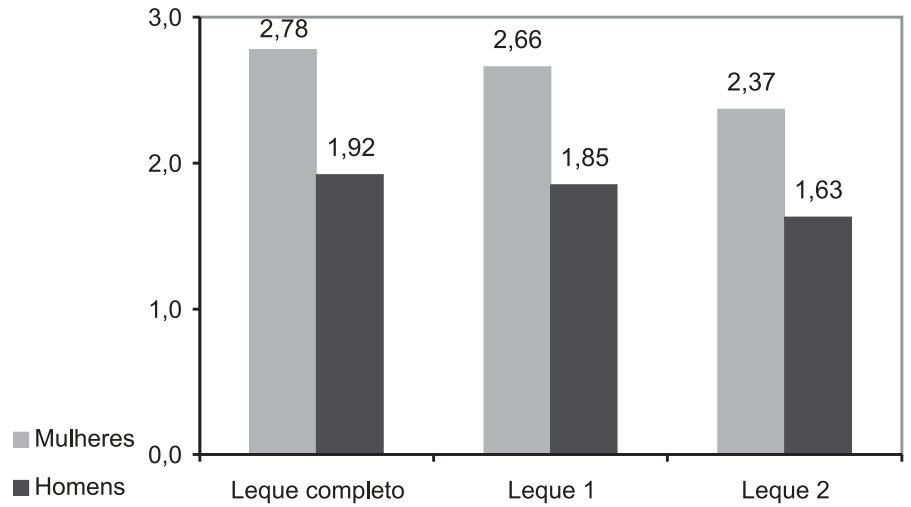

O Gráfico 5 mostra que há uma diferença entre homens e mulheres em cada conjunto de itens que os fazem lembrar da morte de seu parente ou amigo. As três diferenças são significativas no nível de 0,000 . A queda da distribuição da diferença média dos leques de sensibilidade é proporcional à quantidade de itens de cada leque. Há maior número de estímulos que fazem com que as mulheres se lembrem dos que partiram em comparação com os homens.

O grau de parentesco com as vítimas é uma variável relevante para essa análise. Ao testarmos o grau de parentesco/amizade e as lembranças significativas, controlando por gênero, observamos que a diferença é significativa nos dois grupos (feminino e masculino). ${ }^{8}$

\section{Gráfico 6 - Lembrança da morte do parente/amigo, segundo parentesco e gênero}

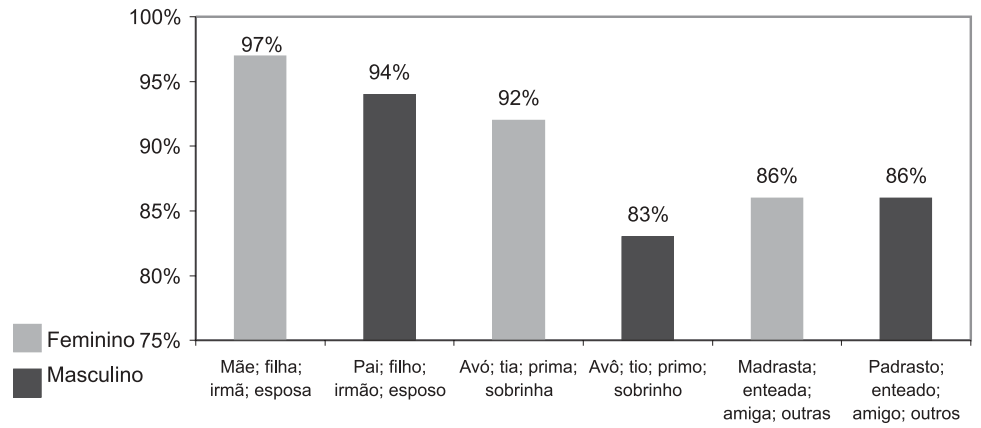


Analisando os resultados do Gráfico 6, percebemos que grau de parentesco é uma variável importante para análise dos que lembram da morte. No primeiro grupo de parentesco composto por mães ou pais, filhas(os), irmãs(ãos) e esposas(os) que responderam que lembram, $96 \%$ eram mulheres e $94 \%$ homens. Nesse grupo, a diferença de gênero é mínima. ${ }^{9}$ Aqui o grau de parentesco sobrepôs o efeito do gênero. Encontramos resultados semelhantes nos demais grupos de parentesco e de amizade. Esses percentuais confirmam a conclusão de muitos estudos, de que os laços de afetividade e parentesco têm relação com a forma e a intensidade de sentir uma perda de um ente querido.

As diferenças entre os gêneros não se limitam a "lembrar ou não lembrar". Entre os que se lembram, há diferenças de intensidade. No Gráfico 7 vemos as diferenças de gênero concernentes à intensidade das lembranças da morte.

\section{Gráfico 7 - Parentes/amigos de vítimas que costumam se lembrar da morte, segundo gênero}

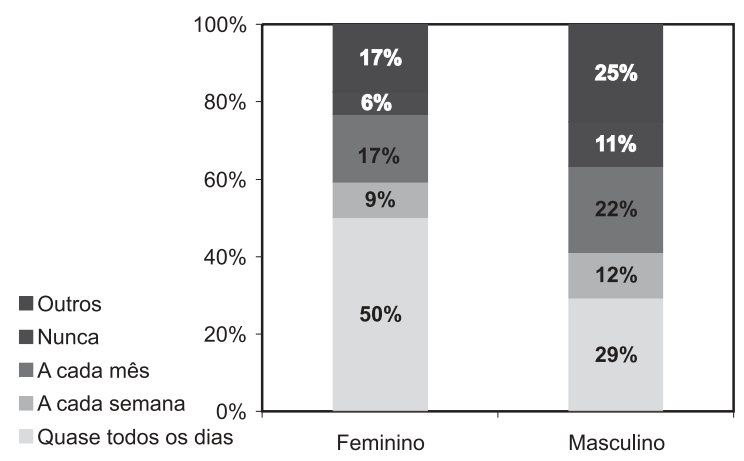

A presença da vítima é marcante na vida de 50\% das mulheres e $29 \%$ dos homens, que se lembram da sua morte quase todos os dias. Os parentes e amigos que nunca se lembram da morte são poucos, representando apenas $6 \%$ das mulheres e $11 \%$ dos homens. Essas diferenças são estatisticamente significativas. ${ }^{10}$ 
Os relatos abaixo descrevem o significado da perda de um parente/amigo para os entrevistados, segundo os fatores desencadeadores da lembrança da morte. Por exemplo, uma jovem que perdeu o seu avô assassinado confessou que datas importantes - aniversários, festas natalinas e de final de ano - são os itens que fazem-na lembrar e sentir com maior freqüência da dor da perda. Nas palavras da jovem moça:

Ah, porque a gente fazia festas não precisava chamar ninguém porque tava todo mundo ali. Depois que meu vô morreu, as pessoas foram desanimando de fazer, foram desanimando de fazer aquilo; ele já faleceu numa data chata: ele faleceu dia 4 de dezembro, próximo ao Natal. Então, toda vez que vai chegando o Natal a gente já sente aquela falta. E eu faço aniversário dia 22 de dezembro, então eu não tenho mais vontade nenhuma de comemorar meu aniversário. Esse ano que compraram um bolo lá, às pressas, aí fizeram contra a minha vontade, mas fizeram. Modifica muito. (Neta de uma vítima de homicídio)

Novamente no relato abaixo, observamos o quanto a lembrança de uma pessoa querida permanece "viva" no cotidiano dos entrevistados. Datas familiares como o Natal perdem o sentido em face de tanta dor e lágrimas. No relato de uma jovem mulher, que perdeu seu irmão por homicídio, está a marca dessa lembrança mesclada com a dor da perda:

Até hoje não tem um dia que eu não pense nela. Todo dia eu lembro, toda festa de Natal. Sabe aquela pessoa que...(chorando muito) qualquer festa ela se fazia presente, ela era muito alegre, muito alegre, muito bonita, linda, morena de olhos verdes e...esse Natal e Ano Novo, esse e o do ano passado, eu viajei porque eu não conseguia parar de chorar o dia inteiro, a noite inteira. (Irmã de uma vítima de homicídio)

Uma forma de lidar com "a dor da perda" é evitá-la. Essa atitude é mais freqüente entre as vítimas ocultas masculinas. Um "velho pai" que perdeu o seu filho por acidente explica que a melhor forma de lidar com a dor é evitar lembrar.

Geralmente, o sr. lembra do acontecido ou não pensa mais nisso?

Não penso mais nisso. Por isso, eu procuro me distrair. (Pai de uma vítima de acidente) 
Outros entrevistados buscam esquecer a dor, evitando lugares, ouvir músicas, ver fotos e outras coisas que os façam lembrar da morte. Nas palavras de filho de uma vítima de homicídio:

[...] (eu evito) alguma coisa que me lembre. Uma música, um louvor ou alguma música que ela gostava como o Renato Russo, Skank...então eu evito essas coisas que me lembram ela. Volta tudo, até coisas como o colégio que a gente estudou. Por exemplo, na eleição eu tive que ir lá, na escola, então cada degrau que eu subia me... (chorando). A gente tem que evitar, isso ajuda. Eu evito ver fotos, evito as coisas que me lembram. (Filho de uma vítima de homicídio)

Concentramos boa parte das entrevistas em sequielas como distúrbios com o sono (dificuldade para dormir, pesadelo), medo de ruídos ou cheiros que lembravam a morte do ente querido, além das reações físicas como vertigens, suor ou cólicas. As reações físicas são menos freqüentes do que as emocionais. Talvez expressem situações mais graves.

\section{Gráfico 8 - Parentes/amigos de vítimas cujas lembranças os motivam a ter reações físicas, segundo gênero}

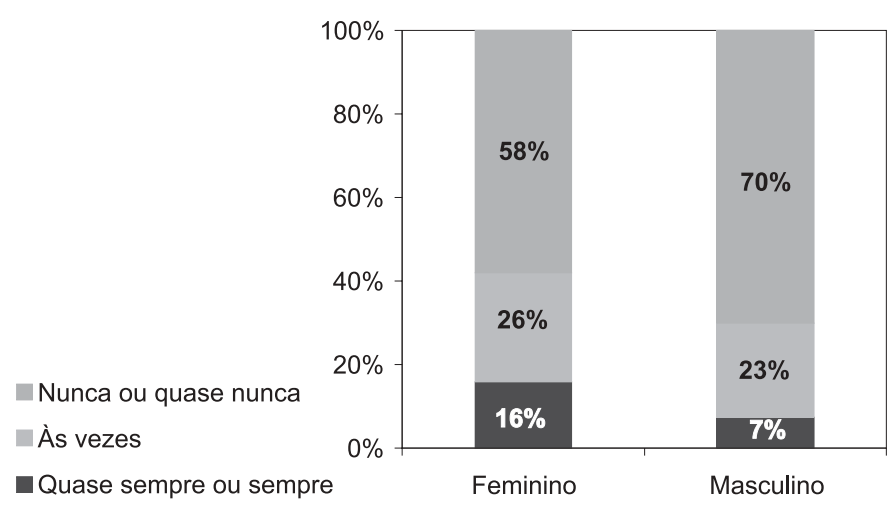

Setenta porcento dos homens e $58 \%$ das mulheres "nunca ou quase nunca" apresentam reações físicas; do outro lado da escala, $16 \%$ das mulheres apresentam essas reações "sempre ou quase sempre”, em comparação com $7 \%$ entre os homens. São diferenças 
estatisticamente significativas. ${ }^{11}$ Há diferenças, também, no que concerne ao sono. Entre os homens, $16 \%$ declararam ter problemas com o sono, bem menos do que os $36 \%$ entre as mulheres. ${ }^{12}$ Os homens também declaram ter menos pesadelos do que as mulheres: $68 \%$ vs $60 \%$. As diferenças são modestas, mas estatisticamente significativas no nível de $0,07 .{ }^{13}$

$\mathrm{Na}$ auto-avaliação do sono, $13 \%$ das mulheres e $7 \%$ dos homens o avaliam como "ruim ou muito ruim". ${ }^{14}$ Como na relação com os pesadelos, é uma diferença modesta, mas significativa. ${ }^{15}$

Os problemas com sono também são mencionados nos relatos de ambos os gêneros como consequiência da experiência traumática. Segundo uma jovem mulher, que perdeu o seu namorado por homicídio, durante os primeiros meses após o incidente o seu sono ficou alterado, juntamente com a sensação de perturbação e medo. Nas palavras da vítima:

Durante uns três meses a gente dormia todo mundo junto. Se eu escutasse o cachorro da vizinha latir já acordava e não conseguia mais dormir, não tinha aquele sono tranqüilo. Qualquer barulho me abalava. (Namorada de uma vítima de homicídio)

Uma outra jovem menina informa que a sua avó, depois da morte do seu pai, passou a ter várias complicações de saúde e de ordem psicológica, como problemas de coração e um forte medo de viver na cidade do Rio de Janeiro.

A minha vó ficou com graves problemas de coração. A minha vó não vem no Rio mais [...] A última vez que ela veio ao Rio, foi pra ela poder resolver coisas da casa que estava pra alugar. Aí eu, assim, do nada, olhei pra minha vó, aí falei: "Vó, o que que está acontecendo? A sua boca tá torta". Ela estava tendo princípio de derrame e ela não estava sentindo. Então todos nós descobrimos que toda vez que ela vem no Rio, ela começa a passar mal. Aí a gente evita que ela venha no Rio. (Neta de uma vítima de homicídio).

As complicações com o sono e a saúde também foram vivenciadas pelos homens. Ao perguntarmos se o entrevistado havia ficado traumatizado, ou obtido algum problema para dormir, uma vítima que perdeu o pai respondeu: 
Eu sou bem traumatizado pelo falecimento do meu pai também. Houve também... mas foi há muito tempo, já tem 13 anos. Aconteceu também isso com o meu pai. Então, isso... ajunta essas coisas tudo só tem mesmo é que ficar com a cabeça quente. Perder um pai assim desse jeito, enganado, morto por engano! Pôxa, perder um filho nessa situação, como é que você vai ficar? Perder mamãe, porque minha mãe foi morte natural! Depois vem pai, vem filho.... como é que a pessoa vai ficar com a cabeça? Toda vida vai ficar [... ] aquilo, meu Deus, como é que pode ser? E só fica pensando em quê? Violência. Como é que tá essa violência? Por mais que a pessoa seja errada, eu sou o tipo de pessoa que eu não gosto mesmo de coisa errada. Eu não suporto ver, Deus me perdoe a pessoa que vive na base de tóxico; ainda mais quando é pessoas que têm condições de ajudar, tem como ajudar, tem um pai que ajuda, tem uma mãe que ajuda, tem pessoas que dá força, dá tudo! $\mathrm{E}$ a pessoa deixar um elemento, dois, três elementos chegar e tirar seu filho de dentro de casa pra trabalhar como usuário de drogas, pra te dar um dinheiro a mais por isso. $\mathrm{E}$ isso não é brincadeira, não. Com toda sinceridade... (sem conter lágrimas - pai de uma vítima de homicídio)

Há, também, diferenças estatisticamente muito significativas entre homens e mulheres relativas aos sintomas emocionais e psicológicos. ${ }^{16}$ Quatro em cada dez mulheres declararam ter reações emocionais sempre que se lembram da morte, aproximadamente o dobro dos homens. Essa diferença permanece quando analisamos as respostas do outro lado do contínuo, os entrevistados que declararam nunca ou quase nunca ter reações emocionais ao lembrar da morte: os homens têm 13 pontos percentuais a mais do que as mulheres. Essa resposta indica que a pessoa não apresenta essas reações e, como esperado, há percentualmente mais homens não afetados do que mulheres.

Os relatos evidenciam que as mulheres entrevistadas são mais emotivas ao relatar o evento de morte e/ou a maneira pelo qual vivenciaram a perda foi mais sofrida psicologicamente. $\mathrm{O}$ medo aparece nas palavras e nas reações faciais da vítima. Quando perguntamos à entrevistada, o que se faz para superar uma situação de perda, ela respondeu: 


\section{Gráfico 9 - Parentes/amigos de vítimas cujas lembranças da morte os motivam a ter reações emocionais, segundo gênero}

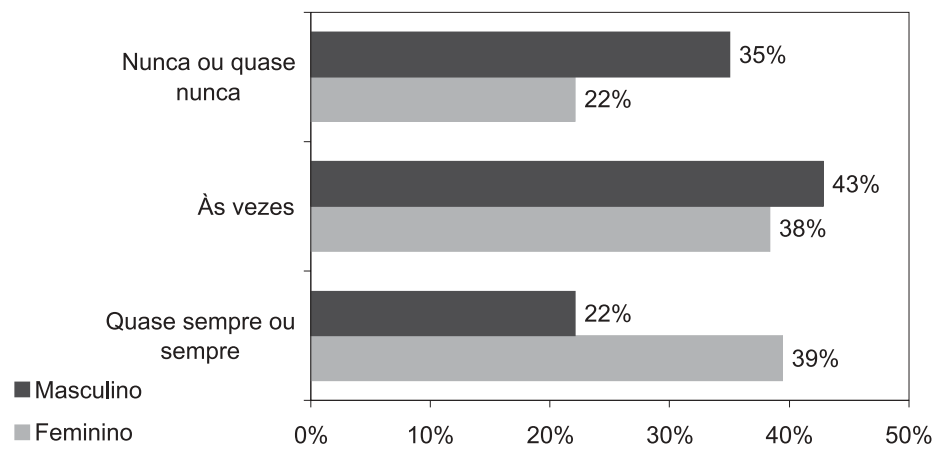

O que me fez superar mesmo foi mais a minha mãe. A minha mãe já sofria e se a gente continuasse a sofrer seria pior para ela. Então, eu botei na cabeça que se eu continuasse quebrando as coisas dentro de casa como eu fazia, ela ia continuar sofrendo. E eu chorando todo dia, eu fazendo tudo que eu fazia, ele também não descansava, entendeu? E eu estava fazendo a minha mãe sofrer mais ainda com o meu sofrimento. Eu resolvi mudar. Eu tinha que sorrir mesmo que eu estivesse sofrendo. E é isso que eu faço. (Irmã de uma vítima de homicídio)

Eu lembro que me perguntaram "Você conhece D. C.?" Eu disse: "Conheço, é minha irmã", "Aqui é o Cabo do $3^{\circ}$ Batalhão de N.... é que ela e o G. foram assassinados". Foi assim que eu recebi a notícia, isso martela na minha cabeça até hoje. Eu perdi a cor, meu marido estava em casa e eu lhe disse "B. mataram a D!" [...] Não tem explicação, parece que é trote, parece que você está sonhando e que vai acordar [...] Olha, durou alguns minutos. Eu lembro que eu estava secando o cabelo dele e fiquei assim... continuei a secar e ele me disse "Mãe, eu vou me queimar". Eu não acreditei, achei que era trote. (Irmã de uma vítima de homicídio)

Não sei, mas a gente fica com essa paranóia na cabeça, com medo de ser assaltada porque eu também moro num lugar muito escuro. Então, eu fiquei dois meses assim, eu descia do ônibus, procurando, olhando para todos os lugares e saía correndo. Então, eu fiquei dois meses com uma sensação muito ruim de medo, medo de ir para faculdade, 
de sair, de tudo. E eu acho que até hoje eu ainda tenho muito isso. Eu acho que hoje eu ando muito mais alerta. O medo ainda está presente. Eu atravesso a rua correndo, só volto para casa correndo [...] A gente começa a ficar com medo das pessoas que estão ao nosso redor. E, de repente, numa briga de vizinho, eu acho que... qualquer coisa vão pegar uma arma e atirar... sei lá. (Namorada de uma vítima de homicídio)

Entre os homens, duas atitudes são comuns: evitar as lembranças do morto ou do incidente e ser "forte" diante da dor: daí terem reações emocionais com menor freqüência e intensidade das mulheres. ${ }^{17}$ Nos relatos abaixo, os entrevistados declaram que, ao invés de lembrar da morte, procuram reter apenas as boas lembranças do seu ente querido. Da mesma maneira, dizem enfrentar essa situação com mais realismo e bravura. Ao perguntarmos ao entrevistado que tipo de conselho ele daria a outras pessoas que tivessem perdido alguém por morte violenta, ele nos disse:

Eu acho que essa pessoa que tem aquela imagem do acontecimento, se conformar, mas não lembrar muito não. Só pensar em coisa boa que essa pessoa fez. Não pensar no desastre, no sinistro. Lembrar somente as coisas boas. (Pai de uma vítima de acidente)

O mesmo pai ressalta a importância de estar "preparado" para enfrentar as contingências da vida. $O$ trecho abaixo expressa essa sensação de "otimismo" combinada com expressões corporais e verbais de "conformismo":

A gente tem que ter força de encarar a realidade da vida, porque a vida ela vai te ensinando. A vida, quando a gente tá nela, ela não tem fim. Se você tá, não tem fim pra isso. A gente tem aquela preocupação no futuro de passar por maus momentos, de outros aí de dentro da sua casa, como se diz; irmãos, que graças a Deus essa felicidade eu tenho. De nenhum ser portador disso. (Pai de uma vítima de homicídio)

Os flashbacks são uma reação particularmente pesada à perda violenta de seres queridos - é o aparecimento de cenas da morte ou do morto sem que as pessoas queiram. Vinte e três por cento das mulheres declararam ter esse sintoma, em comparação com $13 \%$ 
dos homens. Há quem atribua aos flashbacks um alto grau de especificidade, definindo-os como sintomas típicos da DEPT.

\section{Gráfico 10 - Parentes/amigos da vítima, segundo ter flashbacks de cenas relacionadas à morte e gênero}

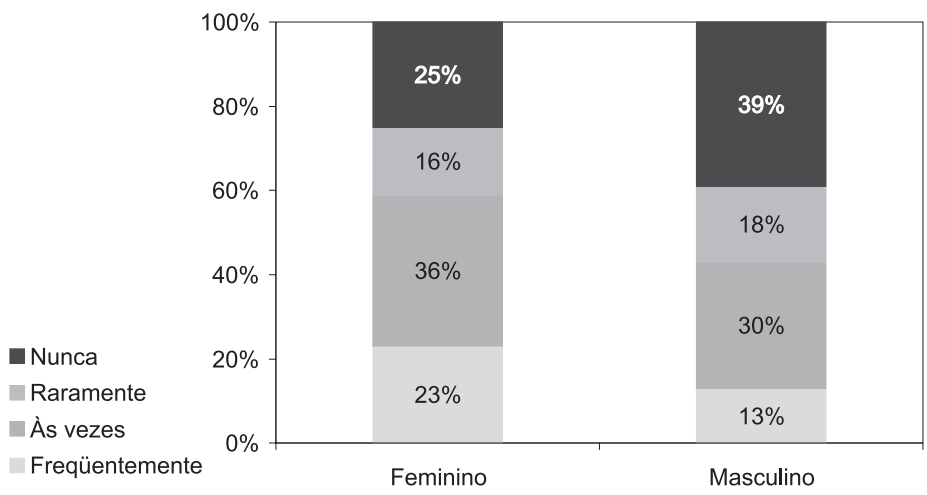

Há, percentualmente, mais mulheres que apresentam esse sintoma, e ele é mais intenso entre elas. Seis em cada dez mulheres declararam que essas cenas apareciam "freqüentemente" ou "às vezes", em comparação com quatro em cada dez dos homens, diferenças que são estatisticamente significativas. ${ }^{18}$

\section{Conclusões}

Dadas essas diferenças de gênero, cabe esclarecer o seu porquê. A que elas podem estar relacionadas? Há várias explicações possíveis. Tomando os resultados literalmente, as mulheres sentiriam mais as perdas do que os homens, através de mecanismos culturais, sociais, psicológicos e biológicos. Porém, também é possível argumentar que as mulheres verbalizariam de forma mais intensa os seus sentimentos, ao passo que os homens o fariam de forma mais discreta. Há outras possibilidades socioculturais que podem ajudar na explicação: as famílias são particularmente instáveis nas áreas mais pobres, nas quais ocorre boa parte da violência, 
particularmente dos homicídios. Os papéis reservados para os homens na educação e no desenvolvimento afetivo das crianças são limitados. A paternidade parece ser menos responsável do que a maternidade. Além disso, muitos homens fazem, durante a vida, uma peregrinação do sexo, desenvolvendo poucos laços afetivos, seja com as mulheres, seja com filhos e filhas. São pais itinerantes. A matrilocalidade é dominante no Brasil. Crianças, adolescentes e até jovens adultos de pais separados ou divorciados quase sempre vivem com a mãe; conseqüentemente, há mais interações entre as crianças, os adolescentes e os jovens adultos com as elas do que com os pais, o que sugere maior intimidade e afetividade, mais contato.

Normalmente, as mulheres passam mais tempo em casa do que os homens e, durante o dia, há mais mulheres nas casas do que homens. Como as vítimas da violência são majoritariamente adolescentes e homens jovens, é possível que essas diferenças expressem, apenas, a diferença na freqüência e na intensidade do contato com os filhos, netos, primos e sobrinhos. Os contatos seriam mais freqüentes entre parentes da mãe do que entre parentes do pai, devido à matrilocalidade.

Resumindo, as entrevistas qualitativas e os dados quantitativos revelaram que: (1) as percepções de medo, ansiedade, estresse e de insegurança são construídas por homens e mulheres de forma diferente, particularmente, no que concerne à percepção cognitiva do trauma; (2) existem diferenças entre homens e mulheres no conviver com essa situação de perda, pois recorrem a mecanismos distintos de sobrevivência; (3) há diferenças do impacto da morte sobre o cotidiano entre homens e mulheres; (4) a forma pela qual as vítimas ocultas se relacionam com a vítima e a sua morte varia com o gênero, com o grau de parentesco e com o contato com o corpo da vítima; (5) as mulheres - mães, esposas, filhas, irmãs - que reconheceram o corpo foram muito afetadas; (6) parte dessas diferenças não são internas aos gêneros, mas externas a eles, dependentes da freqüência e da intensidade das interações, dos contatos pessoais, ou seja, quanto mais fortes os laços afetivos e de solidariedade entre amigos e parentes das vítimas diretas, maior será 
a dor e mais severos serão os sintomas; (7) por último, o conhecimento das variáveis que facilitam ou dificultam lidar com a dor e reatar a própria vida pode contribuir para formular uma política pública inteligente de auxílio às vítimas ocultas, que poderá ser diferenciada de acordo com o tipo de vítima oculta, inclusive o gênero.

\section{Notas}

1 As mortes violentas aqui examinadas referem-se àquelas causadas por homicídios, suicídio e acidentes de trânsito, atropelamento, queda ou acidente de trabalho.

2 Essas dificuldades dizem respeito a endereços errados, com mais de um domicílio e domicílios vazios.

$3 \mathrm{x}^{2}$ de 12,853; no nível de 0,$000 ; \mathrm{gl}=1$; e razão de verossimilhança de 12,918 no nível de significância de 0,$000 ; \mathrm{gl}=1$

$4 \mathrm{x}^{2}$ de 25,096 e gl=1; razão de verossimilhança de 27, 423, no nível de significância de 0,000 e gl=1.

$5 \mathrm{x}^{2}$ de 28,534, p-valor de 0,000;gl=2; razão de verossimilhança de 29,798, no nível de significância de 0,000 e gl=2.

$6 \mathrm{x}^{2}$ de 12,463, p-valor de 0,002 ; gl=2; razão de verossimilhança de 12,587, no nível de significância de 0,002 e gl=2.

7 Os autores agradecem essa cautela a Yuri Suárez Dillon Soares.

8 Entre as mulheres, o x² é de 20,427; p-valor de 0,000; gl=4; razão de verossimilhança de 19,43, no nível de significância de 0,001 e gl=4 e entre os homens, o x é de 9,998; p-valor de 0,040; gl=4; razão de verossimilhança de 11, 324 no nível de significância de 0,023 e gl=4).

9 Talvez em função do "efeito-teto", pois os resultados são muito próximos de $100 \%$.

$10 x^{2}$ é de 29,246; p-valor=0,000; gl=4; razão de verossimilhança de 29,711, no nível de significância de 0,000 e gl=4.

$11 \mathrm{x}^{2}$ de 11,719; p-valor=0,003; gl=2; razão de verossimilhança de 12,36 a nível de significância igual a 0,002 e grau de liberdade $=2$.

$12 \mathrm{x}^{2}$ é de 32,667; $\mathrm{p}$-valor=0,000;gl=1; razão de verossimilhança de 34,651, $\mathrm{p}$-valor $=0,000, \mathrm{gl}=1$ 
$13 \mathrm{x}^{2}$ é de 5,244; $\mathrm{p}$-valor $=0,073 ; \mathrm{gl}=2$; razão de verossimilhança de 5,357, pvalor $=0,069, \mathrm{gl}=2$

$14 \mathrm{x}^{2}$, de 13,270, é significativo no nível de 0,01, com 4 graus de liberdade.

15 Os problemas com o sono são consideravelmente menores do que esperávamos. Talvez as demandas do trabalho e as horas perdidas no transporte deixem pouca opção e muitos durmam por exaustão.

$16 \mathrm{x}^{2}$ de 21,679; p-valor=0,000; gl=2; razão de verossimilhança de 22,188 a nível de significância igual a 0,000 e dois graus de liberdade.

17 É também possível que os homens tenham mais dificuldade em admitir essas reações.

$18 \mathrm{x}^{2}$ de 21,242; $\mathrm{p}$-valor=0,000; $\mathrm{gl}=3$; razão de verossimilhança de 21,488 no nível de significância igual a 0,000 e três graus de liberdade

\begin{abstract}
Gender and trauma
The social and psychological consequences endured by friends and relatives of people victimized by violent death (homicide, suicide or accidents) are analyzed on the light of gender differences. Current literature suggests that women and men face traumatic experiences in different ways. However, traumas also vary by gender, raising questions about how much of the differences are due to gender or to the type of trauma. We hypothesized that women are more susceptible than men to post-traumatic stress disorder (PTSD) when the traumatic event is common. We compared the trauma symptoms and the meaning of the loss of loved ones. A sample of 425 women (62\%) and 265 men (38\%) was drawn from a list of people that suffered violent deaths in the city of Rio de Janeiro and were interviewed in 2003-4. Fifty-four percent of the women and $41 \%$ of the men had their daily routines altered after the death of a relative/friend. There are statistically significant differences concerning health problems and entertainment practices. Half of the interviewees seriously reduced leisure. The contact with the corpse is intimately correlated with the PTSD symptoms. Controlling the extension of the contact (corpse recognition; seeing it, but not recognizing it and not seeing it and not recognizing it), women were more affected than men. The article concludes that women feel the losses more deeply than men, but part of these differences are not "intrinsic" to genders, but depend on social capital, on institutional contacts and personal interactions.
\end{abstract}


Key-words: urban violence, indirect victim, pos-traumatic, stress disorder, PTSD.

\section{Referências bibliográficas}

BRADY, K. T. Post-traumatic stress disorder and comorbidity: recognising the many faces of PTSD. J. Clin. Psychiatry, n. 58, Suppl 9, p. 12-15, 1997.

BRESLAU, N.; KESSLER, R. C.; CHILCOAT, H. D.; SCHULTZ, L. R.; DAVIS, G. C.; ANDRESKI, P. Trauma and post-traumatic stress disorder in the community: the 1996 Detroit area survey of trauma. Arch. Gen. Psychiatry, n. 55, p. 626-632, 1998.

BRESLAU, N.; DAVIS, G. C. Post-traumatic stress disorder in an urban population of young adults: risks factors for chronicity. American Journal of Psychiatry, n. 149, p. 671-675, 1992.

CLOITRE, Marylene. Comorbidity of DSM-IV disorders among women experiencing traumatic events. NCP Clinical Quarterly, v. 7, n. 3, summer 1997.

FOA, E. B.; RIGGS, D.S. Post-traumatic stress disorder in rape victims. In: OLDHAM, J.; RIBA, M. B.; TASMAN, A. (Orgs). Review of Psychiatry. Washington, D.C., v. 12, p. 273-303, 1993.

FOA, E., B.; ROTHBAUM, B. O. Treating the trauma of rape: cognitivebehavioral therapy for PTSD. New York: Guilford Press, 1998.

FOA, E. B.; KOZAK, M. J. Emotional processing of fear: exposure to corrective information. Psychological Bulletin, 99, p. 20-35, 1986.

HALLIGAN, S.L.; MICHAEL, T., CLARK, D. M.; EHLERS, A. Posttraumatic stress disorder following assault: the role of cognitive processing, trauma memory, and appraisals. J. Consult Clin Psychol. v. 71, n. 3, p. 419-31, June 2003.

KILPATRICK, D. G.; RUGGIERO, K. J.; RON, A.; BENJAMIN, E. S.; RESNICK, H. S.; BEST, C. L. Violence and risk of PTSD, major depression, substance abuse/dependence, and comorbidity: results from the national survey of adolescents. Jornal of Consulting and Clinical Psychology, v. 71, n. 4, p. 692-700, 2003.

MAESA, Michael; MYLLEE, Jacques; DELMEIREB, Laure; JANCAF, Alexander. Pre and post-disaster negative life events in relation to 
the incidence and severity of post-traumatic stress disorder. Psychiatry Research, n. 105, p. 1-12, 2001.

MCFARLANE, A. C. The longitudinal course of post-traumatic morbidity: The range of outcomes and their predictors. Journal of Nervous and Mental Disease, n. 176, p. 30-39, 1988.

PONZER, S.; JOHANSSON, M. L.; JOHANSSON, S.). Gender differences in acute somatic and psychological to moderate orthopedic injuries. European Journal of Trauma, n. 1, 2001.

RESNICK, H.; VERONEN, L. J.; SAUNDERS, B.; KILPATRICK, D. G.; CORNELISON, V. Assessment of PTSD in a subset of rape victims at 12 to 36 months post-assault. Manuscrito não publicado, citado em: FOA, Edna B.; ROTHBAUM, Barbara Olasov. Treating the trauma of rape. New York: Guilford Press, 1998. p. 16-17.

ROTHBAUM, B. O.; FOA, E. B.; RIGGS, D.; MURDOCK, T.; WALSH, W. A prospective examination of post-traumatic stress disorder in rape victims. Journal of Traumatic Stress, ), v. 5, p. 455-475, 1992.

SKOGMAN, Katarina; ALSÉN, Margot; OJEHAGEM, Ageta. Sex differences in risk factors for suicide after attempted suicide. Soc Psychiatry Epidemiol n. 39, p. 113-120, 2004.

STEIN, M. B.; WALKER, R. J.; FORDE, D. R. Gender differences in susceptibility stress disorder. Behaviour Research and Therapy, $\mathrm{n}$. 38, p. 619-628, 2000.

STEIN, M. B.; WALKER, R. J.; HAZEN, A. L.; FORDE, D. R.). Full and partial posttraumatic stress disorder: findings from a community survey. American Journal of Psychiatry, n. 154, p. 1114-1119, 1997.

THOMPSON, Martie P.; KASLOW, Nadine J.; KINGREE, J. B. Childhood maltreatment, PTSD, and suicidal behavior among african american females (statistical data included). Journal of Interpersonal Violence, v. 15 , n. 13 , Jan. 2000.

TOLIN, F. D; FOA, E., B.; Gender and PTSD: a cognitive model. In; KIMERLING, R.; QUIMETTE, P.; WOLFE, J. (Ed.). Gender and PTSD. New York: Guildford Publications, 2002. p 76-97.

WELTER, Friederike; KAUTONEN, Teemu; CHEPURENKO, Alexander; MALIEVA, Elena; VENESAAR, Urve. Does trust matter? - a cross cultural view on entrepreneurship in different trust milieus. Trabalho apresentado à College-Kauffman Foundation Entrepreneurship Research Conference, 5-7 june 2003, Babson, USA. 